\title{
EXPOSURE TO CARBON MONOXIDE FROM SECOND- HAND TOBACCO SMOKE IN POLISH PUBS
}

\author{
Maciej Łukasz Goniewicz ${ }^{1,2}$, Jan Czogała ${ }^{1}$, Leon Kośmider ${ }^{3}$, Bartosz Koszowski ${ }^{1}$, Wioleta Zielińska-Danch ${ }^{1}$, \\ Andrzej Sobczak ${ }^{1,4}$ \\ ${ }^{1}$ Department of General and Inorganic Chemistry, Faculty of Pharmacy and Laboratory Medicine, Medical University of Silesia, Sosnowiec, \\ Poland \\ ${ }^{2}$ Center for Tobacco Control Research \& Education, University of California, San Francisco, USA \\ ${ }^{3}$ Students' Science Society, Medical University of Silesia, Sosnowiec, Poland \\ ${ }^{4}$ Department of Chemical Hazards, Institute of Occupational Medicine and Environmental Health, Sosnowiec, Poland
}

\begin{abstract}
SUMMARY
Carbon monoxide (CO) is one of the more toxic agents present in the gas phase of second-hand tobacco smoke. There is sufficient evidence suggesting that passive smokers are involuntarily poisoned by low CO concentrations. At lower doses, $\mathrm{CO}$ affects the central nervous system leading to deterioration in visual perception, manual dexterity, learning, driving performance, and attention level. The effects of chronic inhalation of $\mathrm{CO}$ at doses corresponding to tobacco smoking on the cardiovascular system are not well investigated but might involve myocardial hypertrophy and arrhythmias. In people with pre-existing disease, CO pollution alone may result in increased morbidity and mortality. In the study CO levels were monitored in 22 Polish pubs. The temporary CO concentration varied in examined pubs from 0 to 33.11 ppm. The average 8-hours CO concentration varied from 0.21 to $10.20 \mathrm{ppm}$. Nine percent of pubs exceeded the WHO or EU limit value at some point during the monitoring process. The average weekly $\mathrm{CO}$ concentration in all examined microenvironments varied from 0 to $4.80 \mathrm{ppm}$. The most important factor influencing CO concentration was air-exchange through open doors and windows. In pubs where doors and windows were closed, the following statistical important factors influencing CO concentration were found: 1. the number of smokers present in the pub, 2. the pub's capaciousness, and 3. and the pub's location. The results of the study show that second-hand tobacco smoke is a significant source of CO in Polish pubs. Passive smokers in Polish pubs might be exposed to very high CO concentration exceeding EU reference value.
\end{abstract}

Key words: carbon monoxide, second-hand tobacco smoke, passive smoking, pubs, exposure

Address for correspondence: M. L. Goniewicz, Center for Tobacco Control Research and Education, University of California, San Francisco, 530 Parnassus Ave., Suite 366, Box 1390, San Francisco, CA, USA 94143-1390. E-mail: goniewiczm@medsfgh.ucsf.edu

\section{INTRODUCTION}

Carbon monoxide (CO) is one of the more toxic agents present in the gas phase of tobacco smoke. It is a colourless, odourless, tasteless and non-irritating gas formed when tobacco is not burned completely. It is present in mainstream smoke which is directly inhaled by an active smokers, at levels of 5 to $22 \mathrm{mg} /$ cigarette. The compound can also be found in sidestream smoke and is emitted into the atmosphere during puff breaks, on levels of 9 to $35 \mathrm{mg} /$ cigarette (1). Sidestream tobacco smoke and the smoke exhaled by active smokers are the most important components of second-hand smoke (SHS, also called environmental tobacco smoke - ETS). Thus, SHS might be a significant source of exposure of passive smokers (people breathing air polluted with tobacco smoke) to CO $(2,3)$.

CO rapidly enters the bloodstream and combines with haemoglobin forming carboxyhaemoglobin and thereby reducing oxygen supply to the body tissues and organs. There is sufficient evidence suggesting that passive smokers are involuntarily poisoned by low CO concentrations. At lower doses, CO affects the central nervous system leading to deterioration in visual perception, manual dexterity, learning, driving performance, and attention level (4). The effects of chronic inhalation of CO at doses corresponding to tobacco smoking on the cardiovascular system are not well investigated but might involve myocardial hypertrophy and arrhythmias $(5,6)$. In people with pre-existing disease, CO pollution alone may result in increased morbidity and mortality (7). $\mathrm{CO}$ is one of the priority indoor-originated compounds that were assessed and considered the most hazardous in the three phases of the hazard identification process of the INDEX project ("Critical Appraisal of the Setting and Implementation of Indoor Exposure Limits in EU”) held by the Joint Research Centre of the European Commission (8).

\section{MATERIALS AND METHODS}

\section{Sample Design}

A total of 22 pubs within Silesia region (southern part of Poland) were randomly chosen. None of the pubs were smoke-free. Classification of pubs was performed as follows: 1 . the number 
of smokers present inside, 2. the pub's volume, 3. the type of ventilation, 4 . the location (cellar storey vs. first floor). The average number of smokers present inside the pubs was $2.42 \pm 1.34$. In all examined pubs at least one smoker was present during the monitoring period. $45 \%$ of pubs were small, with capaciousness smaller than $100 \mathrm{~m}^{3}$, in case of $41 \%$ the volume ranged between 101 and $200 \mathrm{~m}^{3}$, and only $14 \%$ were large with volume greater than $201 \mathrm{~m}^{3} .41 \%$ of pubs were ventilated through open doors and/or windows and only $18 \%$ were equipped with electronic air-conditioning systems. $63 \%$ of pubs were located in the cellar storey and the rest were on the first floor.

CO levels were monitored in the examined pubs in the evening during seven consecutive days in autumn 2007. Indoor air samples were taken every half of an hour during 8 hours everyday. The samples were collected directly into polyethylene bags $\left(2 \mathrm{dm}^{3}\right)$ using a pump (Bestway, USA). Then the samples were taken to a laboratory and analyzed within 24 hours as described below.

\section{Carbon Monoxide Analysis}

$\mathrm{CO}$ was quantified in the collected samples according to the method published previously (2). In brief, CO was analyzed using GC-FID CX 3800 (Varian, USA) equipped with $0.25 \mathrm{ml}$ gas sample loop that allowed a sample injection directly on the chromatography column from the sampling bags. A $30 \mathrm{~m} \times$ $0.53 \mathrm{~mm}$ ID $\times 50 \mu \mathrm{m}$ Molesive 5A PLOT column (Supelco, USA) was used. After separation on the column, CO was converted to methane using $10 \%$ nickel nitrate on a Chromosorb G AW $100 / 120$ and temperature of $360^{\circ} \mathrm{C}$ in order to allow its detection. The column and detector temperatures were $30^{\circ} \mathrm{C}$ and $250{ }^{\circ} \mathrm{C}$, respectively. The flow rate of $\mathrm{He}$ (carrier gas) was $3 \mathrm{ml} / \mathrm{min}$, and the flow rates for $\mathrm{H}_{2}$ and air were 30 and $300 \mathrm{ml} / \mathrm{min}$, respectively. Retention time of CO was $6.37 \mathrm{~min}$. The intra- and inter-day precisions of the method were $2.95 \%$ and $5.17 \%$, respectively, and the limit of detection was $0.20 \mathrm{ppm}$.

\section{Results Analysis}

The CO concentrations are given in parts per million [ppm v/v] units $\left(1 \mathrm{ppm}=1145 \mu \mathrm{g} / \mathrm{m}^{3}\right)$. The average 8-hours and weekly concentration of $\mathrm{CO}$ in each from examined pubs was calculated as weighted mean. The average 8-hours CO concentrations were compared to the WHO and EU limit value for carbon monoxide which is $10 \mathrm{mg} / \mathrm{m}^{3}$ (9 ppm) $(9,10)$. The mean CO concentration values were compared using ANOVA tests. Multivariable analysis was used to find factors influencing indoor $\mathrm{CO}$ concentration in the examined pubs. All statistical calculations were performed using Statistica software (Statsoft Corp., USA).

\section{RESULTS}

CO concentrations in a single sample (temporary concentration) varied from 0 to 33.11 ppm. Fig. 1 presents changes in CO indoor air levels during a short time of the same one-day examination period (four exemplary pubs, O, T, P, and Z, monitored at the same time). The average 8-hours CO concentration in all examined pubs was $1.04 \pm 1.87 \mathrm{ppm}$ and varied from 0.21 to $10.20 \mathrm{ppm}$. Nine percent of pubs exceeded the WHO or EU limit value at some point during the monitoring process. The average weekly CO concentration in all examined microenvironments was $0.97 \pm 1.39 \mathrm{ppm}$ and varied from 0 to $4.80 \mathrm{ppm}$ depending on the examined pub. Weekly mean concentration and daily ranges are presented in Fig. 2. The highest temporary, 8-hours and weekly CO concentration levels of 33.11, 10.20 and 4.80 ppm, respectively, were observed in the same place: a small students' pub situated on the first floor with capaciousness of $37.5 \mathrm{~m}^{3}$, with limited ventilation and three smokers present, on average. In four examined pubs CO levels were below the detectable level during the whole monitoring period.

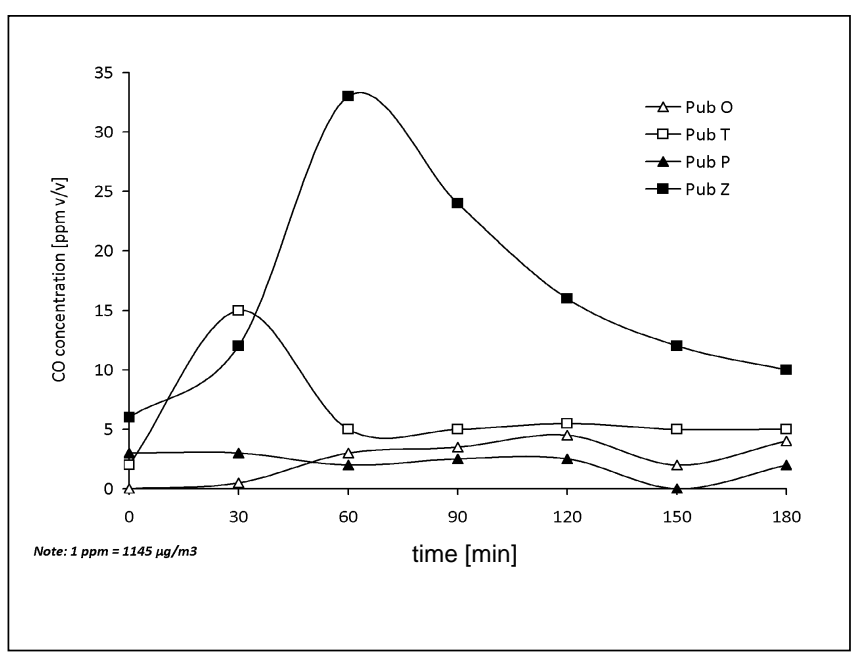

Fig. 1. Intra-day variations in CO concentration in four selected pubs.

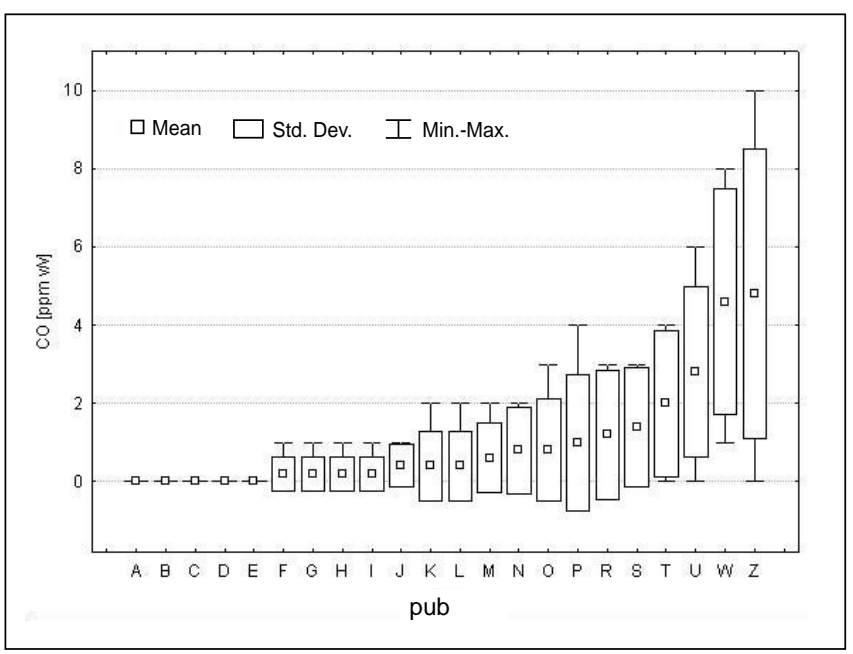

Fig. 2. Box and whisker plot of weakly average concentrations of $\mathrm{CO}$ in examined pubs (whiskers correspond to inter-day variations in CO concentration). $1 \mathrm{ppm}=1,145 \mu \mathrm{g} / \mathrm{m}^{3}$.

The most important factor influencing CO concentration in pubs was air ventilation through open doors and windows ( $p=0.0002)$. In the case of pubs where doors and windows were closed, the following statistically important factors influencing CO concentration were found: 1 . the number of smokers present in the pub ( $p=0.0140), 2$. the pub's volume $(p=0.0477)$, and 3. its location (cellar storey vs. first floor, $p=0.0060$ ). 


\section{DISCUSSION}

The results from the study show that CO levels in all examined microenvironments depend on tobacco smoke (ambient CO levels did not exceed $0.35 \mathrm{ppm}$ ). Although CO was monitored during autumn season, we did not find any other sources of this gas in the examined pubs (gas cooking in the kitchen, gas heating). Moreover, the indoor air ventilation was increased by open windows. The average weekly CO concentrations found in the course of the study were similar to results reported previously for indoor microenvironments with presence of SHS (11). These results also showed, that passive smokers can be exposed to very high CO concentration exceeding the WHO or EU reference value.

The results indicate that the pub's location (cellar storey vs. first floor) is one of the statistically vital factors that influence CO indoor levels. It is very significant for countries like Poland where many pubs are located in a cellar storey. As a result, pubs of this type are characterized by poor ventilation. The impact of the type and rate of ventilation system employed was also significant in pubs located on the first floor. However, data obtained previously from pubs in Manchester (from 2006, before the implementation of smoking ban in the UK) showed that whatever the ventilation type there was no evidence that SHS levels in pubs of high smoking rate might be near any hazard level (12). The effect of ventilation might not be significant for less volatile tobacco smoke components like vapour-phase nicotine and respirable suspended particles but seems to be significant for highly volatile compounds like CO. Some research projects performed in other countries proved that second-hand tobacco smoke is a major source of indoor air contamination in public hospitality venues including pubs. Indoor air monitoring in 28 public hospitality venues in Germany performed this year proved that tobacco smoke was the main source of many toxic or carcinogenic compounds (13).

In Poland, as in many other European countries, there is the on-going debate on smoke-free legislation, which might lead to a complete smoking ban in all kinds of public hospitality venues such as pubs, clubs, restaurants and discotheques. Implementation of the legislation should be supported by sufficient data concerning air quality in public places and health consequences of breathing air polluted with second-hand tobacco smoke. The results presented in this article prove that passive smoking in public places like pubs might be a potential health risk because of breathing air with elevated levels of CO. Moreover, pubs' patrons and staff are a special group occupationally exposed to higher levels of $\mathrm{CO}$ for a long time. From a public health point of view, effective measures are necessary to protect these employees from CO exposure. There is strong evidence that only a complete smoking ban is effective in reducing SHS exposure in public hospitality venues like pubs (14-17).

\section{Acknowledgements}

This work was supported by Medical University of Silesia [KNW-2035/08]. Results of the study were presented as a poster during the 45th Congress of the European Societies of Toxicology, October 5-8, 2008, Rhodes, Greece.

\section{REFERENCES}

1. Czogała J, Goniewicz MŁ. Carbon monoxide levels in main- and sidestream smoke from cigarettes of selected brands and estimation of active and passive smokers exposure to this compound. Ann Pol Chem Soc. 2003;2(1):316-20.

2. Czogala J, Goniewicz MŁ. The complex analytical method for assessment of passive smokers' exposure to carbon monoxide. J Anal Toxicol. 2005 Nov-Dec;29(8):830-4.

3. Bernstein JA, Alexis N, Bacchus H, Bernstein IL, Fritz P, Horner E, et al. The health effects of non-industrial indoor air pollution. J Allergy Clin Immunol. 2008 Mar;121(3):585-91.

4. Raub JA, Benignus VA. Carbon monoxide and the nervous system. Neurosci Biobehav Rev. 2002 Dec;26(8):925-40.

5. Srrhhaug S, Steinshamn S, Nilsen OG, Waldum HL. Chronic inhalation of carbon monoxide: effects on the respiratory and cardiovascular system at doses corresponding to tobacco smoking. Toxicology. 2006 Dec 7;228(23):280-90.

6. Sari I, Zengin S, Ozer O, Davutoglu V, Yildirim C, Aksoy M. Chronic carbon monoxide exposure increases electrocardiographic P-wave and QT dispersion. Inhal Toxicol. 2008 Jul;20(9):879-84.

7. Wright J. Chronic and occult carbon monoxide poisoning: we don't know what we're missing. Emerg Med J. 2002 Sep;19(5):386-90.

8. Koistinen K, Kotzias D, Kephalopoulos S, Schlitt C, Carrer P, Jantunen $\mathrm{N}$, et al. The INDEX project: executive summary of a European Union project on indoor air pollutants. Allergy. 2008 Jul;63(7):810-9.

9. Directive 2000/69/ec of the European Parliament and of the Council of 16 November 2000 relating to limit values for benzene and carbon monoxide in ambient air. Off J Eur Community. 2000 Dec 13;43(L313):12-21.

10. World Health Organization [homepage on the Internet]. Guidelines for air quality [cited 2008 Oct 22]. Available from: http://whqlibdoc.who. int/hq/2000/WHO_SDE_OEH_00.02_pp1-104.pdf, http://whqlibdoc. who.int/hq/2000/WHO_SDE_OEH_00.02_pp105-190.pdf.

11. De Bruin YB, Carrer P, Jantunen M, Hänninen O, di Marco GS, Kephalopoulos S, et al. Personal carbon monoxide exposure levels: contribution of local sources to exposures and microenvironment concentrations in Milan. J Expo Anal Environ Epidemiol. 2004 Jul;14(4):312-22.

12. Gee IL, Watson AF, Carrington J, Edwards PR, van Tongeren M, McElduff P, et al. Second-hand smoke levels in UK pubs and bars: do the English Public White Paper proposals go far enough? J Public Health (Oxf). 2006 Mar;28(1):17-23.

13. Bolte G, Heitmann D, Kiranoglu M, Schierl R, Diemer J, Koerner W, et al. Exposure to environmental tobacco smoke in German restaurants, pubs and discotheques. J Expo Sci Environ Epidemiol. 2008 May;18(3):26271.

14. Repace JL, Hyde JN, Brugge D. Air pollution in Boston bars before and after a smoking ban. BMC Public Health. 2006 Oct 27;6:266.

15. Wilson N, Edwards R, Maher A, Näthe J, Jalali R. National smokefree law in New Zealand improves air quality inside bars, pubs and restaurants. BMC Public Health. 2007 May 18;7:85.

16. Gorini G, Chellini E, Galeone D. What happened in Italy? A brief summary of studies conducted in Italy to evaluate the impact of the smoking ban. Ann Oncol. 2007 Oct;18(10):1620-2.

17. Haw SJ, Gruer L. Changes in exposure of adult non-smokers to secondhand smoke after implementation of smoke-free legislation in Scotland: national cross sectional survey. BMJ. 2007 Sep 15;335(7619):549-52.

Received January 5, 2009 Accepted in revised form April 15, 2009 